\title{
Synthesis of a series of pyrazoline derivatives carrying tosyl substitution and evaluation of their antimicrobial properties
}

\author{
Shubhalaxmi $^{\mathrm{a}}$, B. S. Manjunatha ${ }^{\mathrm{a}}$, K. Ananda ${ }^{\mathrm{b}}$, K. Subrahmanya Bhat ${ }^{\mathrm{a}^{*}}$ \\ ${ }^{a}$ Department of Chemistry, Manipal Institute of Technology, Manipal University, Manipal-576 104, India. \\ ${ }^{\mathrm{b} B i o l o g i c a l ~ S c i e n c e s ~ D i v i s i o n, ~ P o o r n a p r a j n a ~ I n s t i t u t e ~ o f ~ S c i e n t i f i c ~ R e s e a r c h, ~ D e v a n a h a l l i, ~ B a n g a l o r e-562 ~ 164, ~ I n d i a . ~}$
}

\section{ARTICLE INFO \\ Article history: \\ Received on: 22/06/2016 \\ Revised on: 30/07/2016 \\ Accepted on: 22/08/2016 \\ Available online: 29/11/2016}

Key words:

2-Pyrazolines; Chalcones;

Antimicrobial properties.

\begin{abstract}
A series of pyrazoline derivatives with tosyloxy substitution were synthesized and characterized. They were evaluated for antimicrobial potential against Mycobacterium smegmatis, gram positive Staphylococcus aureus, gram negative Escherichia coli, and a fungi Candida albicans. The initial screening using zones of inhibition at $50 \mu \mathrm{L}$ concentrations revealed that they are moderately active against the tested strains, and therefore further studies have not been carried out.
\end{abstract}

\section{INTRODUCTION}

The antimicrobial agents with novel structural characteristics are increasingly in demand due to antimicrobial resistanceto the prescribed drugs (Bogatcheva et al., 2006).Various strategies are adopted to find newer drugs among them are synthesis of small chemical entities, complex molecular structures, and metal complexes of organic ligands or isolation of structural lead from natural plant products or from marine resources (Muller, 2003).

Other strategies are to synthesize novel molecules based on hybrid pharmacophores, where two or more therapeutically useful structural units are combined with appropriate chemical linkages (Kalaria et al., 2014). Pyrazoline compounds are having significant biological activities as they are structurally related to the pyrazolone family of drugs. Among isomeric pyrazoline

* Corresponding Author

Email: sbkjrf@yahoo.co.in derivatives, 1,2-pyrazolines are the most thermodynamically stable and therefore are explored widely for a range of biological applications, including antitubercular, antioxidant, anticancer and as antidepressant agents. Due to their biological significance, a variety of structural modifications have been achieved around pyrazoline ring (Ghorab et al., 2010; Rostom et al., 2003; Yeu et al., 2001; Amnerkar et al., 2010). We have recently explored the synthesis and antimicrobial activity of a series of compounds having aryloxy substituents attached to pyrazoline ring providing moderate antimicrobial action.

Introduction of tosyl group at an aromatic ring gives new molecules that can be utilized to probe their biological potential as well as further derivatization of such molecules are possible as tosyl group is easily replaceable with many nucleophiles. In one example, we have described the synthesis and antimicrobial properties of newer pyrimidinethione derivatives possessing tosyl substituents (Shubhalaxmi et al., 2016).In this paper, we report the synthesis, characterization and antimicrobial screening of a series of pyrazoline derivatives. 


\section{MATERIALS AND METHODS}

All reagents were used as procured from commercial suppliers and used without further purification. The melting points were determined in open capillaries, using Thomas Hoover melting point apparatus and expressed in ${ }^{\circ} \mathrm{C}$. The reactions were monitored using TLC for completion and compounds were checked for purity by TLC on silica gel-G (Merck grade). Infrared spectra (IR) were recorded on Schimadzu 8400S Infrared Spectrophotometer using potassium bromide $(\mathrm{KBr})$ pellets and the values are expressed in $\mathrm{cm}^{-1}$. The ${ }^{1} \mathrm{H}$ NMR spectra of the compounds were recorded on Bruker Ascend $400 \mathrm{MHz}$ NMR spectrophotometer using TMS as an internal standard and the values are expressed in $\delta$ ppm.

\section{EXPERIMENTAL}

\section{Procedure for the synthesis of chalcones}

The required chalcones were synthesized by aldol condensation of the corresponding aldehydes and ketones. The detailed synthetic procedure and their characterization data were given in our earlier publications (Shubhalaxmi et al., 2016; Shubhalaxmi, Manjunatha et al., 2016)

\section{Procedure for the synthesis of pyrazoline derivatives (1a-f, 2 a-f)}

The various pyrazoline derivatives are synthesized by reacting chalcone derivatives with excess of hydrazine hydrate in presence of catalytic amount glacial acetic acid for 3-6 hours at 70 $-80^{\circ} \mathrm{C}$. The formation of the products were identified by thin layer chromatography and completion of the reaction is monitored. The products were recovered by pouring the reaction mixture into ice cold water or in few cases crystals were developed after keeping the mother liquor overnight. The products were isolated by filtration, dried and recrystallized from suitable solvent. The $R_{f}$ values were reported using mobile phase of hexane: ethylacetate (2:0.9).

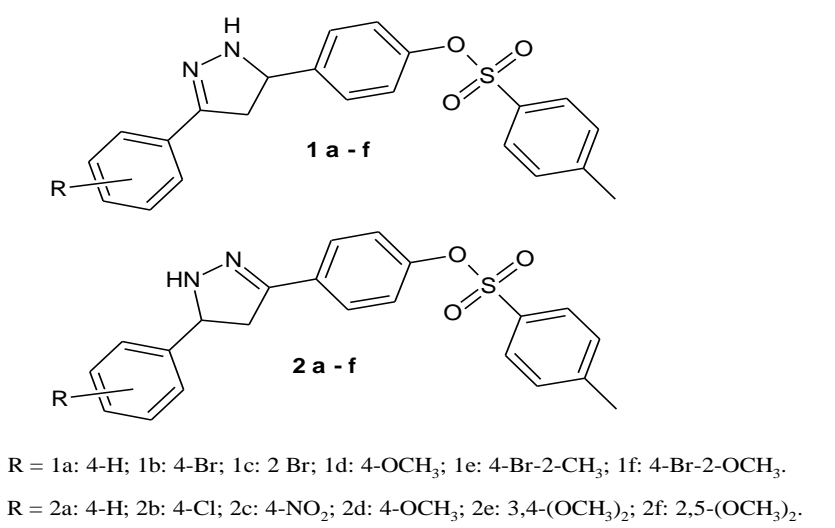

1a:4-(3-phenyl-4,5-dihydro-1 $H$-pyrazol-5-yl) pheny l-4methylbenzene-1-sulfonate: yield: $70 \%$, m.p.:98-100 ${ }^{\circ} \mathrm{C}$, $\mathrm{R}_{\mathrm{f}}=0.63 ; \mathrm{IR}\left(\mathrm{cm}^{-1}\right): 3340(\mathrm{~N}-\mathrm{H} \mathrm{str}), 3070(\mathrm{C}-\mathrm{H}$ str), 3039 and 2823 (asym, sym C-H str of $\mathrm{CH}_{3}$ ), 1504 (C=N str), 1157 and 1200 (asym, sym $\mathrm{SO}_{2}$ str) $;{ }^{1} \mathrm{H}$ NMR (DMSO, $\left.\delta \mathrm{ppm}\right): \quad 2.472(\mathrm{~s}, 3 \mathrm{H}$, $\left.\mathrm{CH}_{3}\right), 2.76-2.83(\mathrm{q}, 1 \mathrm{H}, \mathrm{H}$ of pyrazoline ring), $4.81-4.86(\mathrm{t}, 2 \mathrm{H}, \mathrm{H}$ of pyrazoline ring), $7.00-7.76(\mathrm{~m}, 14 \mathrm{H}$, aromatic $\mathrm{H})$.

\section{1b : 4-[3-(4-bromophenyl) -4,5-dihydro-1H-pyrazol-5-} yl]phenyl-4-methylbenzene-1-sulfonate: yield - $63 \%$, m. p.: 82$84^{\circ} \mathrm{C}, \mathrm{R}_{\mathrm{f}}=0.6$; IR $\left(\mathrm{cm}^{-1}\right): 3355(\mathrm{~N}-\mathrm{H}$ str), 3062 (arC-H str), 2885 (C-H str) $1504\left(\mathrm{C}=\mathrm{N}\right.$ str), 1195 and 1157 (asym, sym SO 2 str); ${ }^{1} \mathrm{H}-$ NMR (DMSO, $\delta$ ppm): 2.425 (s, 3H, $\mathrm{CH}_{3}$ ), 2.51-3.359 (q, $1 \mathrm{H}, \mathrm{H}$ of pyrazoline ring), $4.89-4.93$ (t, $2 \mathrm{H}, \mathrm{H}$ of pyrazoline ring), 7.00 $-7.76(\mathrm{~m}, 1 \mathrm{H}, 13 \mathrm{H}$, aromatic $\mathrm{H})$.

1c: 4-[3-(2-bromophenyl)-4,5-dihydro-1H-pyrazol-5-yl]phenyl4-methylbenzene-1-sulfonate: yield - $63 \%$, m. p. : $76-78^{\circ} \mathrm{C}, \mathrm{R}_{\mathrm{f}}=$ 0.6; IR $\left(\mathrm{cm}^{-1}\right): 3363$ (N-H str), $3224(\mathrm{C}-\mathrm{H} \mathrm{str}), 2893$ and 3062 (asym,symC-H str) 1504(C=N str), 1172 and 1149 (asym,sym $\mathrm{SO}_{2} \mathrm{str}$ ); ${ }^{1} \mathrm{H}$ - NMR (DMSO, $\delta \mathrm{ppm}$ ): 2.425 (s, $3 \mathrm{H}, \mathrm{CH}_{3}$ ), 2.513.359 (q, $1 \mathrm{H}, \mathrm{H}$ of pyrazoline ring), $4.89-4.93(\mathrm{t}, 2 \mathrm{H}, \mathrm{H}$ of pyrazoline ring), $7.00-7.76(\mathrm{~m}, 13 \mathrm{H}$,aromatic $\mathrm{H})$.

1d: 4-[3-(4-methoxyphenyl) -4,5-dihydro-1H-pyrazol-5yl]phenyl-4-methylbenzene-1-sulfonate: yield - $59 \%$, m. p.: 68$70{ }^{\circ} \mathrm{C}, \mathrm{R}_{\mathrm{f}}=0.59 ; \mathrm{IR}\left(\mathrm{cm}^{-1}\right): 3340$ (N-H str), 3047 (arC-H str), 2916 and 2839 (asym, sym C-H str) $1504(\mathrm{C}=\mathrm{N}$ str), 1172 and 1149 (asym,sym $\mathrm{SO}_{2}$ str); ${ }^{1} \mathrm{H}-\mathrm{NMR}$ (DMSO, $\delta \mathrm{ppm}$ ): 2.425 (s, $3 \mathrm{H}$, $\left.\mathrm{CH}_{3}\right), 2.51-3.359$ (q, $1 \mathrm{H}, \mathrm{H}$ of pyrazoline ring), $4.28\left(\mathrm{~s}, 3 \mathrm{H}, \mathrm{OCH}_{3}\right.$ ), $4.89-4.93(\mathrm{t}, 2 \mathrm{H}, \mathrm{H}$ of pyrazoline ring), $7.00-7.76$ (m,13H,aromatic $\mathrm{H})$.

1e: 4-[3-(2-bromo-4-methylphenyl) -4,5-dihydro- $1 H$-pyrazol-5yl]phenyl-4-methylbenzene-1-sulfonate:yield - $67 \%$, m. p. - 112 ${ }^{\circ} \mathrm{C}, \mathrm{R}_{\mathrm{f}}=0.6 ; \mathrm{IR}\left(\mathrm{cm}^{-1}\right): 3356$ (N-H str), $3210(\mathrm{C}-\mathrm{H} \mathrm{str}), 2889$ and 3060 (asym, sym C-H str) 1504(C=N str), 1172 and 1149 (asym, sym $\mathrm{SO}_{2} \mathrm{str}$ ); ${ }^{1} \mathrm{H}$ - NMR (DMSO, $\delta$ ppm):1.21 (s, $3 \mathrm{H}, \mathrm{CH}_{3}$ ), 2.425 (s, $3 \mathrm{H}, \mathrm{CH}_{3}$ ), 2.51-3.359 (q, $1 \mathrm{H}, \mathrm{H}$ of pyrazoline ring), $4.89-4.93$ $(\mathrm{t}, 2 \mathrm{H}, \mathrm{H}$ of pyrazoline ring $), 7.00-7.76(\mathrm{~m}, 12 \mathrm{H}$, aromatic $\mathrm{H})$.

1f: 4-[3-(2-bromo-4-methoxyphenyl) -4,5-dihydro-1H-pyrazol5-yl]phenyl-4-methylbenzene-1-sulfonate:yield - $78 \%$, m. p. $120{ }^{\circ} \mathrm{C}, \mathrm{R}_{\mathrm{f}}=0.62 ; \mathrm{IR}\left(\mathrm{cm}^{-1}\right): 3340$ (N-H str), 3047 (arC-H str), 2916 and 2839 (asym, sym C-H str) $1504(\mathrm{C}=\mathrm{N}$ str), 1172 and 1149 (asym,sym $\mathrm{SO}_{2}$ str); ${ }^{1} \mathrm{H}-\mathrm{NMR}$ (DMSO, $\delta$ ppm): 2.425 (s, $3 \mathrm{H}$, $\left.\mathrm{CH}_{3}\right), 2.51-3.359$ (q, $1 \mathrm{H}, \mathrm{H}$ of pyrazoline ring), 4.312 (s, $3 \mathrm{H}$, $\mathrm{OCH}_{3}$ ), $4.89-4.93$ (t, $2 \mathrm{H}, \mathrm{H}$ of pyrazoline ring), $7.00-7.76$ (m,12H,aromatic $\mathrm{H})$.

2a:4-(5-phenyl-4,5-dihydro-1H-pyrazol-3-yl) phenyl-4methylbenzene-1-sulfonate: yield $-78 \%$, m. p. $-91-93{ }^{\circ} \mathrm{C}, \mathrm{R}_{\mathrm{f}}=$ 0.45; IR( $\left(\mathrm{cm}^{-1}\right): 3348$ (N-H str), 3193 (ar C-H str), 2923 and 2854 (asym, sym C-H str) 1504 (C=N str), 1365 and 1203 (asym,sym $\mathrm{SO}_{2} \mathrm{str}$ ); ${ }^{1} \mathrm{H}$ - NMR (DMSO, $\delta$ ppm): 2.425 (s, $3 \mathrm{H}, \mathrm{CH}_{3}$ ), 2.782.84(q, $1 \mathrm{H}, \mathrm{H}$ of pyrazoline ring), $4.82-4.87(\mathrm{t}, 2 \mathrm{H}, \mathrm{H}$ of pyrazoline ring), $7.01-7.76(\mathrm{~m}, 14 \mathrm{H}, \mathrm{Ar}-\mathrm{H})$. 
2b: 4-[5-(4-chlorophenyl)-4,5-dihydro-1H-pyrazol-3-yl]phenyl4-methylbenzene-1-sulfonate: yield - $59 \%$, m. p. $-96-98{ }^{\circ} \mathrm{C}, \mathrm{R}_{\mathrm{f}}$ $=0.5 ; \operatorname{IR}\left(\mathrm{cm}^{-1}\right): 3362(\mathrm{~N}-\mathrm{H}$ str), 3055 (ar C-H str), 2939 and 2792 (asym,sym C-H str), 1504 (C=N str), 1342 and 1195 (asym, sym $\mathrm{SO}_{2}$ str); ${ }^{1} \mathrm{H}-\mathrm{NMR}$ (DMSO, $\delta$ ppm): 2.402 (s, 3H, $\mathrm{CH}_{3}$ ), 2.51-2.79 (q, 1H, H of pyrazoline ring), $3.739\left(\mathrm{~s}, 3 \mathrm{H}, \mathrm{OCH}_{3}\right), 4.81-4.83(\mathrm{t}$, $2 \mathrm{H}, \mathrm{H}$ of pyrazoline ring), 7.01- $7.75(\mathrm{~m}, 13 \mathrm{H}, \mathrm{Ar}-\mathrm{H})$.

\section{2c. 4-[5-(4-nitrophenyl) -4,5-dihydro-1H-pyrazol-3-yl]phenyl-} 4-methylbenzene-1-sulfonate: M. W. - 437, yield - $61 \%$, m. p. 120-122 ${ }^{\circ} \mathrm{C}, \mathrm{R}_{\mathrm{f}}=0.42$; IR( $\mathrm{cm}^{-1}$ ): 3355 (N-H str), 3078 (ar C-H str), 2846 and 2800 (asym, sym C-H str), 1519 (C=N stretching), 1365 and 1342 (asym, symSO2 str); ${ }^{1} \mathrm{H}-\mathrm{NMR}$ (DMSO, $400 \mathrm{MHz}, \delta$ ppm): 2.421 (s, 3H, $\mathrm{CH}_{3}$ ), 2.50-2.87 (q, 1H, $\mathrm{H}$ of pyrazoline ring), 5.00-5.03 (t, 2H, H of pyrazoline ring), 7.01-8.23 (m, 13H, Ar-H).

\section{2d: 4-[5-(4-methoxyphenyl) -4,5-dihydro-1H-pyrazol-3-}

yl]phenyl-4-methylbenzene-1-sulfonate:yield - $42 \%$, m. p. - 153 ${ }^{\circ} \mathrm{C}, \mathrm{R}_{\mathrm{f}}=0.3 ; \mathrm{IR}\left(\mathrm{KBr}, \mathrm{cm}^{-1}\right): 3362$ (N-H str), 3055 (ar C-H str), 2939 and 2792 (asym,sym C-H str), 1504 (C=N str), 1342 and 1195 (asym, sym $\mathrm{SO}_{2}$ str); ${ }^{1} \mathrm{H}-\mathrm{NMR}$ (DMSO, $\delta$ ppm): 2.402 (s, $3 \mathrm{H}, \mathrm{CH}_{3}$ ), 2.51-2.79 (q, 1H, $\mathrm{H}$ of pyrazoline ring), 3.739 (s, $3 \mathrm{H}$, $\left.\mathrm{OCH}_{3}\right), 4.81-4.83(\mathrm{t}, 2 \mathrm{H}, \mathrm{H}$ of pyrazoline ring), 7.01- $7.75(\mathrm{~m}$, $13 \mathrm{H}, \mathrm{Ar}-\mathrm{H})$.

2e: 4-[5-(3,4-dimethoxyphenyl) -4,5-dihydro-1H-pyrazol-3yl]phenyl-4-methylbenzene-1-sulfonate:yield - $64 \%$, m. p. - 94$96^{\circ} \mathrm{C}, \mathrm{R}_{\mathrm{f}}=0.3$; IR(KBr, cm $\left.{ }^{-1}\right): 3317$ (N-H str), 2970 (arC-H str), 2846 and 2800 (asym, sym C-H str) 1592 (C=N str), 1255 and 1226 (asym,sym SO ${ }_{2}$ str); ${ }^{1} \mathrm{H}$ - NMR (DMSO, $\delta$ ppm): 2.503 (s, 3H, $\mathrm{CH}_{3}$ ), 2.50-2.82 (q, $1 \mathrm{H}, \mathrm{H}$ of pyrazoline ring), $3.351\left(\mathrm{~s}, 3 \mathrm{H}, \mathrm{OCH}_{3}\right.$ ), $3.739\left(\mathrm{~s}, 3 \mathrm{H}, \mathrm{OCH}_{3}\right), 4.71-4.76(\mathrm{t}, 2 \mathrm{H}, \mathrm{H}$ of pyrazoline ring), 6.82$8.25(\mathrm{~m}, 12 \mathrm{H}, \mathrm{Ar}-\mathrm{H})$.

\section{2f: 4-[5-(2,5-dimethoxyphenyl) -4,5-dihydro-1H-pyrazol-3-} yl]phenyl-4-methylbenzene-1-sulfonate:yield - $74 \%$, m. p. $112-114{ }^{\circ} \mathrm{C}, \mathrm{R}_{\mathrm{f}}=0.3 ; \mathrm{IR}\left(\mathrm{KBr}, \mathrm{cm}^{-1}\right): 3325(\mathrm{~N}-\mathrm{H}$ str$), 2962(\operatorname{arC}-\mathrm{H}$ str), 2862 and 2810 (asym, sym C-H str) 1596 (C=N str), 1256 and 1222 (asym,sym SO $\mathrm{S}_{2} \mathrm{str}$ ); ${ }^{1} \mathrm{H}$ - NMR (DMSO, $\delta$ ppm): 2.508 (s, 3H, $\mathrm{CH}_{3}$ ), 2.46-2.878 (q, $1 \mathrm{H}, \mathrm{H}$ of pyrazoline ring), $3.351(\mathrm{~s}, 3 \mathrm{H}$, $\left.\mathrm{OCH}_{3}\right), 3.739\left(\mathrm{~s}, 3 \mathrm{H}, \mathrm{OCH}_{3}\right), 4.72-4.768(\mathrm{t}, 2 \mathrm{H}, \mathrm{H}$ of pyrazoline ring), 6.82- 8.25 (m, 12H, Ar-H).

\section{Antimicrobial Activity}

The antimicrobial property of the synthesized compounds 1 a-f and 2a-f was evaluated by well diffusion method in nutrient agar media. Inhibition zones of the test compounds against microorganisms considered qualitatively suggest the antimicrobial potential (Sathish et al., 2012). $12 \mathrm{~h}$ old bacterial culture of a tuberculosis variant bacteria Mycobacterium smegmatis (MTCC 944), gram positive bacteria Staphylococcus aureus (MTCC 3160), and gram negative bacteria Escherichia coli (MTCC 1687) were taken for the in vitro antibacterial evaluation of compounds (Palomino et al., 2002). Antifungal activity of the compounds were tested against pathogenic fungi Candida albicans (MTCC 7253). The bacterial and fungal cultures were obtained from the microbial type culture collection, IMTECH, Chandigarh, India and maintained the cultures as per the standard protocol. About 15-20 $\mathrm{mL}$ of nutrient agar media was poured into each petri plate and allowed to solidify for 15 minutes inside laminar air flow chamber. About $100 \mu \mathrm{L}$ of $0.5 \mathrm{McF}$ arland standard of bacterial/fungal suspension was inoculated on the agar media and spread on the whole surface by swabbing with sterile cotton buds. Than $5 \mathrm{~mm}$ wells were dig on the seeded agar plates with a sterile cork borer. Working solutions of the test compounds is prepared in DMSO at $10 \mathrm{mg} / \mathrm{mL}$ as stock and were poured at different concentrations (25 and $50 \mu \mathrm{g} \mathrm{mL}^{-1}$ ) in to the wells in triplicates. The test plates were incubated at $37{ }^{\circ} \mathrm{C}$ for $12 \mathrm{~h}$ before observing for the zone of inhibition, which is measured in millimeter. DMSO was used as a negative control. Ciprofloxacin was used as antibacterial standard and fluconozole as antifungal standard (10 mcg discs).

\section{RESULTS AND DISCUSSION}

\section{Chemistry}

The title compounds were synthesized starting from hydroxy acetophenones and hydroxy aldehydes by introducing tosyl substitution, as per the procedure described in detail in our previous publication (Shubhalaxmi et al., 2016). The structures of all the compounds were confirmed using FT-IR and ${ }^{1} \mathrm{H}$ NMR. The absence of the carbonyl peak of chalcones around $1650 \mathrm{~cm}^{-1}$ and the appearance of additional peaks due to $\mathrm{NH}$ stretch at around $3200 \mathrm{~cm}^{-1}$ along with $\mathrm{C}=\mathrm{N}$ stretch at around $1550 \mathrm{~cm}^{-1}$ confirms the formation of pyrazoline ring. The presence of $\mathrm{S}=\mathrm{O}$ asymmetric and symmetric stretching bands in FTIR spectra of the compounds also prove that tosyl substitution is unaffected under the experimental conditions. The PMR spectrum of the compound 1a show peaks at 2.4 for $\mathrm{CH}_{3}$ group of tosyl moiety, 2.76-2.83 due to $\mathrm{H}$ of pyrazoline ring, $4.81-4.86$ for $2 \mathrm{H}$ of pyrazoline ring, and the remaining aromatic protons appeared as multiplets in the range 7.00-7.76.In many cases, the NH protons were merged in the aromatic range and therefore not assigned separately.

\section{Biological Evaluation}

The zones of inhibition revealed that the compounds screened are moderately active towards all the tested gram positive bacteria. There were no inhibition zones exhibited against gram negative bacteria, E.coli, implying that these compounds are inactive against similar bacteria. Few of the compounds showed moderate zones of inhibition against the fungi considered for the study, C.albicans. It may be noted that the compounds without substitution at 4 of the aromatic ring, 2a, showed highest inhibition zone against $M$. smegmatis. The compound $\mathbf{2 b}$, with4-chloro substitution in aromatic ring showed remarkably higher inhibition zone against $S$. aureus. The compounds 1a, $2 \mathbf{a}$ and $2 \mathbf{e}$ without substitution at aromatic rings and 3,4-dimethoxy substitution gave highest inhibition zones against $C$. albicans at $50 \mu \mathrm{L}$ concentrations. 
Table 1: Antimicrobial activity of synthesized compounds by well diffusion assay.

\begin{tabular}{|c|c|c|c|c|c|c|}
\hline \multirow{3}{*}{$\begin{array}{l}\text { Synthesized } \\
\text { compounds }\end{array}$} & \multicolumn{6}{|c|}{ Inhibition Zone in mm; Mean \pm SD } \\
\hline & \multicolumn{2}{|c|}{ M.smegmatis } & \multicolumn{2}{|c|}{ S.aureus } & \multicolumn{2}{|c|}{ C.albicans } \\
\hline & $50 \mu \mathrm{L}$ & $25 \mu \mathrm{L}$ & $50 \mu \mathrm{L}$ & $25 \mu \mathrm{L}$ & $50 \mu \mathbf{L}$ & $25 \mu \mathbf{L}$ \\
\hline $\mathbf{1 a}$ & - & - & $14.66 \pm 1.52$ & $7.66 \pm 1.52$ & $17.00 \pm 1.00$ & $13.33 \pm 2.08$ \\
\hline $\mathbf{1 b}$ & - & - & $10.66 \pm 0.57$ & - & $12.0 \pm 00$ & $11.0 \pm 0$ \\
\hline 1d & - & - & - & - & $12.33 \pm 0.57$ & $12.0 \pm 0$ \\
\hline 1e & $12.33 \pm 0.57$ & $10.33 \pm 0.57$ & $12.66 \pm 0.57$ & $12.33 \pm 0.57$ & $16.66 \pm 1.15$ & $13.66 \pm 0.57$ \\
\hline $\mathbf{2 a}$ & $16.66 \pm 0.57$ & $14.33 \pm 0.57$ & $13.66 \pm 0.57$ & $11.66 \pm 0.57$ & $22.33 \pm 0.57$ & $18.66 \pm 0.57$ \\
\hline $2 \mathrm{c}$ & $15.66 \pm 0.57$ & $13.33 \pm 0.57$ & $17.33 \pm 0.57$ & - & $16.00 \pm 0$ & $11.33 \pm 0.57$ \\
\hline $2 d$ & - & - & $10.33 \pm 0.57$ & - & $9.33 \pm 0.57$ & - \\
\hline $2 e$ & - & - & $16.66 \pm 0.57$ & $11.66 \pm 0.57$ & $17.66 \pm 0.57$ & $13.00 \pm 0$ \\
\hline $2 f$ & - & - & - & - & $16.66 \pm 1.15$ & $9.66 \pm 0.57$ \\
\hline ABS/AFS & $46.67 \pm 0.58$ & & $33.33 \pm 0.58$ & & $30.27 \pm 1.55$ & \\
\hline
\end{tabular}

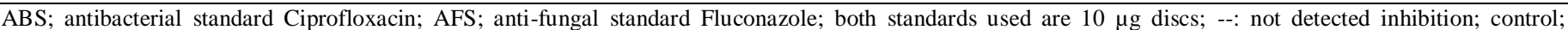

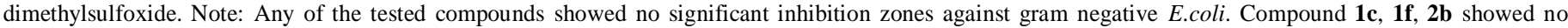
inhibition against any of the tested organisms.

\section{CONCLUSION}

A series of 2-pyrazoline derivatives of different tosyloxy substituted chalcones were synthesized. Some of these compounds are positional isomers of one another. The synthesized compounds were characterized by spectral techniques and structures were assigned. The compounds were subjected to qualitative screening for their antimicrobial potential using well diffusion assay with drug Ciprofloxacin, and Fluconazole for antibacterial and antifungal action as standards respectively. Some of the compounds showed moderate zones of inhibition at $50 \mu \mathrm{L}$ concentration. We intend to extend the scope of the present work by replacing tosyl group with better biologically active substituents by nucleophilic substitution.

\section{ACKNOWLEDGEMENTS}

We thank Central Instrumentation Facility of Manipal Institute of technology, Manipal University for carrying out ${ }^{1} \mathrm{H}$ NMR characterization of the compounds reported in this paper.

Financial support and sponsorship: Shubhalaxmi is grateful to Manipal University for fellowship under the grant of MU structured Ph.D program.

Conflict of Interests: There are no conflicts of interest.

\section{REFERENCES}

Amnerkar ND, Bhusari KP, Synthesis, anticonvulsant activity and 3D-QSAR study of some prop-2-eneamido and 1-acetyl-pyrazolin derivatives of aminobenzothiazole. Eur J Med Chem. 2010; 45(1): 149-59.

Bogatcheva E, Hanrahan C, Nikonenko B, Samala R, Chen P, Gearhart J, Barbosa F, Einck L, Nacy CA, Protopopova M, Identification of new diamine scaffolds with activity against Mycobacterium tuberculosis. J Med Chem. 2006; 49(11): 3045-8.

Ghorab MM, Ragab FA, Alqasoumi SI, Alafeefy AM, Aboulmagd SA, Synthesis of some new pyrazolo [3,4-d]pyrimidine derivatives of expected anticancer and radioprotective activity. Eur J Med Chem. 2010; 45(1): 171-8.

Kalaria PN, Satasia SP, Raval DK, Synthesis, identification and in vitro biological evaluation of some novel 5-imidazopyrazole incorporated pyrazoline and isoxazoline derivatives. New J Chem. 2014; 38(7): 2902-10.

Muller G, Medicinal chemistry of target family-directed masterkeys. Drug Discovery Today. 2003; 8(15): 681-91.

Palomino JC, Martin A, Camacho M, Guerra H, Swings J, Portaels F, Resazurin microtiter assay plate: simple and inexpensive method for detection of drug resistance in Mycobacterium tuberculosis. Antimicrob Agents Chemother. 2002; 46(8): 2720-2.

Rostom SAF, Shalaby MA, El-Demellawy MA, Polysubstituted pyrazoles, part 5. Synthesis of new 1-(4-chlorophenyl)-4-hydroxy-1Hpyrazole-3-carboxylic acid hydrazide analogs and some derived ring systems. A novel class of potential antitumor and anti-HCV agents. Eur J Med Chem. 2003; 38(11-12): 959-74.

Sathish L, Pavithra N, Ananda K, Antimicrobial activity and biodegrading enzymes of endophytic fungi from eucalyptus. Int J Pharm Sci Res. 2012; 3(8): 2574-84.

Shubhalaxmi, Manjunatha BS, Ananda K, Bhat KS, Pyrimidinethione derivatives with tosyl substitution: Synthesis, and antimicrobial property investigation. J App Pharm Sci. 2016; 6(6), 73-78.

Shubhalaxmi, Pathak L, Ananda K, Bhat KS, Synthesis of focused library of novel aryloxyacids and pyrazoline derivatives: Molecular docking studies and antimicrobial investigation. Cogent Chem. 2016; 2, 1141388.

Yeu J-P, Yeh J-T, Chen T-Y, Uang B-J, An Expedient Synthesis of 1-[3-(Dimethylamino)propyl]-5-methyl-3-phenyl-1Hindazole (FS-32) - An Antidepressant. Synthesis. 2001; (12): 1775-7.

\section{How to cite this article:}

Shubhalaxmi, Manjunatha BS, Ananda K, Bhat KS. Synthesis of a series of pyrazoline derivatives carrying tosyl substitution and evaluation of their antimicrobial properties. J App Pharm Sci, 2016; 6 (11): 214-217. 